\title{
ESTUDO DO CRESCIMENTO DE SALMONELLA EM OVOS LÍQUIDOS REFRIGERADOS A DIFERENTES TEMPERATURAS
}

\author{
M. DECKER ${ }^{1}$, A.C.GALVÃO ${ }^{1}$ e W.S. ROBAZZA ${ }^{1}$ \\ ${ }^{1}$ Universidade do Estado de Santa Catarina, Departamento de Engenharia de Alimentos \\ E-mail para contato: wrobazzi@yahoo.com.br
}

\begin{abstract}
RESUMO - A preocupação com uma alimentação saudável vem aumentando à medida que cresce a população. A ausência de microrganismos patogênicos nos alimentos é uma exigência de órgãos de fiscalização. Entre estes, a Salmonella é uma constante fonte de preocupações para a indústria. O objetivo deste trabalho foi estudar através de um modelo matemático o crescimento de Salmonella em ovos líquidos armazenados a diferentes temperaturas. Os dados de crescimento foram obtidos para temperaturas entre $10^{\circ} \mathrm{C}$ e $35^{\circ} \mathrm{C}$. O ajuste dos dados ao modelo de Baranyi foi feito com o DMFit comumente usado neste tipo de análise. Verificou-se que a taxa de crescimento especifico cresceu com o aumento da temperatura. $\mathrm{O}$ valor obtido à $35^{\circ} \mathrm{C}$ foi 21 vezes superior ao obtido para $10^{\circ} \mathrm{C}$. $\mathrm{O}$ período de adaptação diminuiu com a temperatura. A dependência da vida útil com a temperatura é bem acentuada, com valores bem baixos para altas temperaturas. Este tipo de análise pode fornecer informações úteis para o consumo de alimentos.
\end{abstract}

\section{INTRODUÇÃO}

A preocupação com uma alimentação digna e de qualidade vem aumentando à medida que cresce a população global e isso acaba envolvendo questões que relacionam não apenas a quantidade e diversidade de alimentos, mas a qualidade da alimentação através da consciência e aumento do conhecimento dos consumidores de alimentos. A incidência global de doenças causadas por alimentos é de difícil estimativa. No entanto, no ano de 2000 cerca de 2,1 milhões de pessoas morreram por doenças diarreicas e em uma alta proporção destes casos, a causa é atribuída a alimentos contaminados. A procura por alimentos seguros tem crescido cada vez mais devido aos inúmeros casos de intoxicações envolvendo micro-organismos e alimentos contaminados no processamento ou provindos de matérias-primas contaminadas. A ausência de micro-organismos patogênicos, nos produtos de origem animal, é uma exigência de órgãos de fiscalização tanto nacionais como internacionais. Entre os micro-organismos patogênicos, a Salmonella é uma constante fonte de preocupações para a indústria de produtos avícolas (Funk et al., 2001).

As bactérias do gênero Salmonella pertencem à família Enterobacteriacea, são bastonetes gram-negativos, não formadores de esporos, anaeróbios facultativos, reduzem nitratos a nitritos, fermentadoras de glicose e raramente de lactose, crescendo em temperaturas de $35-37^{\circ} \mathrm{C}$ e $\mathrm{pH}$ entre 6,5 e 7,5 (Gyles et al., 1993). De acordo com Silva Jr (2001), a temperatura para multiplicação de Salmonella varia entre $8^{\circ} \mathrm{C}$ e $47^{\circ} \mathrm{C}$. A taxa de crescimento máxima ocorre por volta de $35^{\circ} \mathrm{C}$ e o 


\section{9 a 22 de outubro de 2014 \\ Florianópolis/SC}

crescimento pode ser impedido pelas condições do substrato (acidez ou alcalinidade). Alimentos com alto teor de atividade de água e proteínas também são mais propensos ao desenvolvimento do microorganismo.

A infecção por Salmonellaentericaveiculada por alimentos é uma realidade na maioria dos países, pois, apesar de haver surtos associados ao consumo dos mais variados alimentos, os produtos de origem animal possuem papel de destaque como fonte de infecção para o consumidor (Cardoso; Carvalho, 2006). Segundo Hald (1999), na Dinamarca, entre as fontes de infecção humana, 40-45\% são provenientes de ovos e 10-15\% produtos de origem suína. Dessa forma, é possível perceber que a segurança de produtos de origem animal através do controle da bactéria é um ponto fundamental para se evitar as infecções e intoxicações. De acordo com Darwin e Miller (1999), em seres humanos a infecção ocorre via fecal-oral, sendo a dose necessária para que isto ocorra igual a $10^{5} \mathrm{UFC} / \mathrm{g}$.

A Salmonella habita os intestinos de aves de corte e poedeiras o que justifica o alto índice de contaminações envolvendo produtos obtidos a partir de ovos como a maionese. Conforme Costalunga e Tondo (2002), 48,1\% das salmoneloses alimentares ocorridas no Rio Grande do Sul no período de 2000 a 2001 foram provocadas por maionese caseira. Além disso, foi observado um caso de intoxicação de 480 funcionários em um frigorífico catarinense após a ingestão de produtos de origem aviária (Reis, 2006).

A microbiologia preditiva é uma ferramenta útil na predição do crescimento de populações de micro-organismos. Baseia-se na premissa de que é possível estimar, através do uso de modelos matemáticos criados através de estudos quantitativos dos micro-organismos, o crescimento destes nos alimentos (McMeekin et al., 1993). Como a tecnologia empregada nos diagnósticos de casos de intoxicações alimentares tem evoluído e problemas relacionados a micro-organismos tem se tornado cada vez mais comuns, os estudos visando predizer o crescimento de micro-organismos em alimentos e a deterioração causada por estes receberam destaque nos últimos anos. $\mathrm{O}$ verdadeiro poder das abordagens feitas pela microbiologia preditiva é que, ao contrário do processo tradicional de armazenamento, os modelos, uma vez validados, podem ser utilizados para predizer com rapidez e segurança a resposta dos micro-organismos sob várias condições, dentro dos limites investigados para temperatura, $\mathrm{pH}$ e concentração de sal. Isto faz com que a microbiologia preditiva seja considerada uma ferramenta preciosa para os microbiologistas de alimentos na tomada de decisão diária (McClure et al., 1994).

O objetivo deste trabalho é estudar através de um modelo matemático o crescimento de Salmonella em ovos líquidos armazenados a diferentes temperaturas. $\mathrm{O}$ ovo na forma liquida pode ser empregado em diversos processos na indústria sendo que por vezes é armazenado e submetido a diferentes temperaturas por períodos de tempo que podem levar ao desenvolvimento do microorganismo.

\section{MATERIAIS E MÉTODOS}

Os dados experimentais de crescimento de Salmonella em ovos a diferentes temperaturas foram 
retirados da literatura (Singh et al., 2011) sendo selecionadas para este estudo as temperaturas de $10^{\circ} \mathrm{C}, 15^{0} \mathrm{C}, 25^{\circ} \mathrm{C}, 30^{\circ} \mathrm{C}$ e $35^{\circ} \mathrm{C}$ para comparação do crescimento do micro-organismo.

Para realizar o ajuste aos dados experimentais para o modelo de Baranyi, o qual é o mais utilizado na área da microbiologia preditiva (Baranyi; Roberts, 1994) foi utilizado o software DMFit, o qual consiste num suplemento do Excel que permite estimar e visualizar parâmetros e curvas de crescimento de micro-organismos em alimentos (Combase, 2009). Os demais ajustes foram realizados com o Microsoft Excel 2003. O modelo de Baranyi é proveniente da solução de um sistema composto por duas equações diferenciais e sua solução pode ser descrita na literatura especializada (Baranyi; Roberts, 1994).

\section{RESULTADOS E DISCUSSÃO}

As Figuras 1, 2, 3, 4 e 5 apresentam, respectivamente, os ajustes dos dados experimentais de crescimento às temperaturas de $10^{\circ} \mathrm{C}, 15^{\circ} \mathrm{C}, 25^{\circ} \mathrm{C}, 30^{\circ} \mathrm{C}$ e $35^{\circ} \mathrm{C}$ para o modelo de Baranyi. Pode ser observado que para todas as temperaturas utilizadas neste estudo, foi obtido um bom ajuste conforme pode ser indicado pelo coeficiente de determinação $\left(R^{2}\right)$, o qual foi superior a 0,98 em todos os ajustes realizados neste estudo.

A partir do ajuste aos dados experimentais foram obtidos parâmetros biológicos de crescimento do micro-organismo. Os parâmetros estimados foram: o tempo de duração da fase $\operatorname{lag}(\lambda)$, que corresponde ao período de adaptação do micro-organismo ao alimento, a taxa de crescimento especifico máxima $\left(\mu_{\max }\right)$, que corresponde à velocidade de aumento do logaritmo da população durante o período exponencial de crescimento e o aumento logarítmico líquido $(A)$ da população de micro-organismos. A Tabela 1 apresenta os resultados obtidos para esses parâmetros.

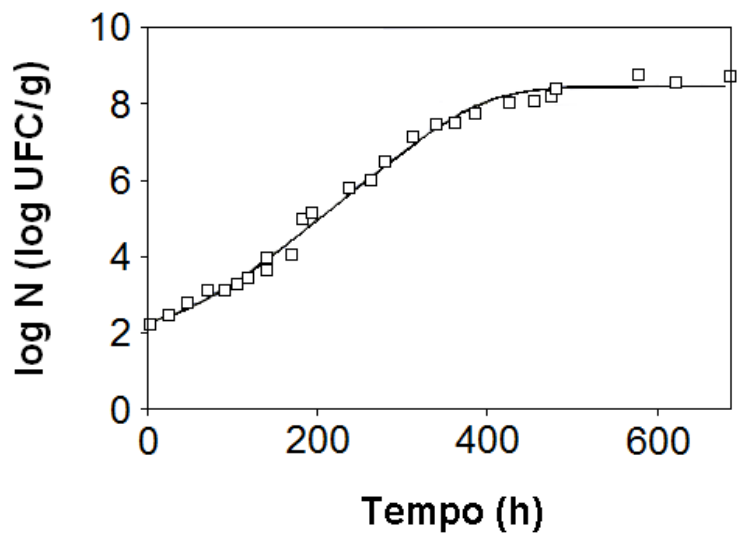

Figura 1 - Ajuste obtido para a temperatura de $10^{\circ} \mathrm{C}\left(\mathrm{R}^{2}=0,996\right)$. 


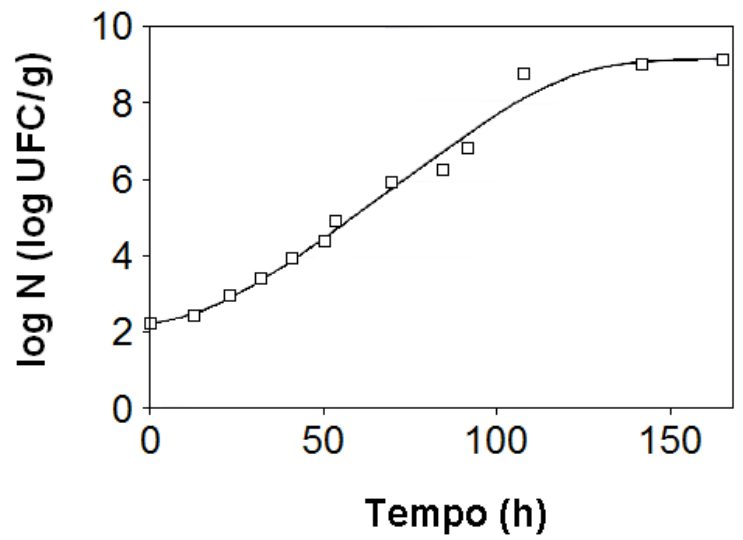

Figura 2 - Ajuste obtido para a temperatura de $15^{\circ} \mathrm{C}\left(\mathrm{R}^{2}=0,984\right)$.



Figura 3 - Ajuste obtido para a temperatura de $25^{\circ} \mathrm{C}\left(\mathrm{R}^{2}=0,994\right)$.

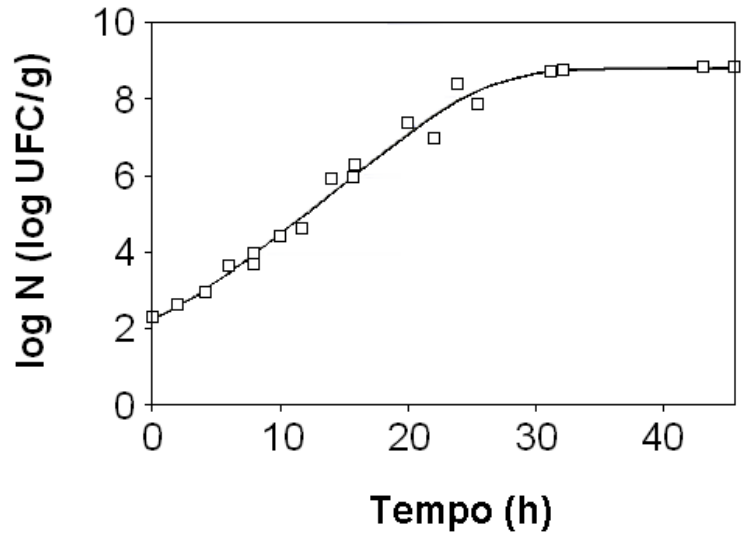

Figura 4 - Ajuste obtido para a temperatura de $30^{\circ} \mathrm{C}\left(\mathrm{R}^{2}=0,990\right)$. 


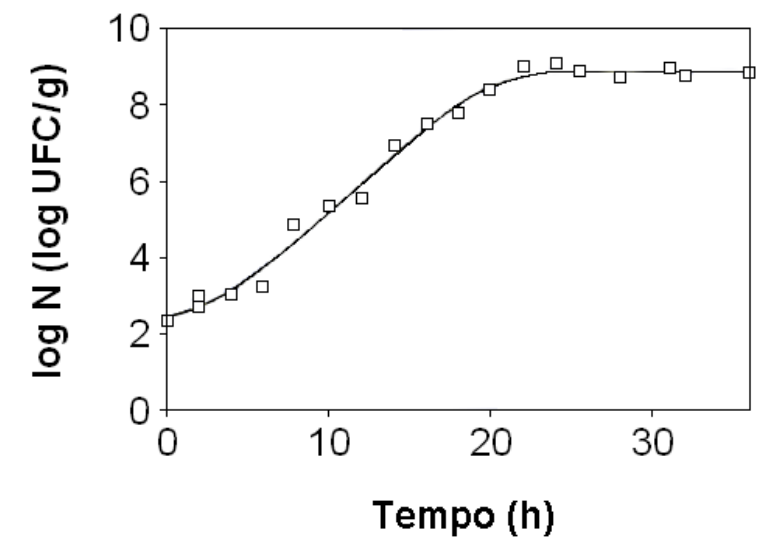

Figura 5 - Ajuste obtido para a temperatura de $35^{\circ} \mathrm{C}\left(\mathrm{R}^{2}=0,989\right)$.

Tabela 1 - Parâmetros biológicos estimados para as temperaturas deste estudo.

$\begin{array}{ccccc}\text { Temperatura } & \lambda(\mathrm{h}) & \mu_{\max }(1 / \mathrm{h}) & A(\log \mathrm{UFC} / \mathrm{g}) & \text { Vida Útil }(\mathrm{h}) \\ 10 & 51,3016 & 0,0179 & 6,1536 & 62,3541 \\ 15 & 17,0384 & 0,0670 & 6,9325 & 58,6427 \\ 25 & 6,0970 & 0,1899 & 6,5922 & 21,4782 \\ 30 & 1,7458 & 0,2658 & 6,5167 & 11,9203 \\ 35 & 2,8258 & 0,3784 & 6,4292 & 10,4772\end{array}$

A partir dos dados da Tabela 1, é possível verificar que a taxa de crescimento especifica máxima para o micro-organismo considerado, conforme esperado, cresceu com o aumento da temperatura. $\mathrm{O}$ valor obtido para a temperatura de $35^{\circ} \mathrm{C}$ foi aproximadamente 21 vezes superior ao obtido para $10^{\circ} \mathrm{C}$. A Equação1 foi obtida de forma empírica expressa a dependência de $\mu_{\max }$ com a temperatura $\left(\mathrm{R}^{2}=0,999\right)$ :

$$
\mu_{\max }(T)=-0,01525+0,00065 T+0,00030 T^{2}
$$

O período de adaptação, em geral diminuiu com a temperatura, exceto para as temperaturas altas, onde se encontra a faixa de crescimento ótimo da Salmonella. A partir dos parâmetros obtidos, foi possível estimar a vida útil dos ovos líquidos do ponto de vista microbiológico, considerando-se este como sendo o tempo necessário para que a população de micro-organismos seja igual a $10^{5}$ UFC/g (5 logaritmos). É importante ressaltar que para todas as temperaturas estudadas, a quantidade inicial de inoculo foi de aproximadamente 2,1 logaritmos. Conforme esperado, a dependência da vida útil com a temperatura é bem acentuada, com valores bem baixos para altas temperaturas.

\section{CONCLUSÕES}

Este trabalho teve por objetivo estudar, através da aplicação de um modelo matemático, o crescimento de Salmonella em ovos armazenados a diferentes temperaturas. Os resultados obtidos 
indicaram que este micro-organismo pode se desenvolver cerca de 21 vezes mais rápido a $35^{\circ} \mathrm{C}$ do que a $10^{\circ} \mathrm{C}$, e que ele se adapta mais rapidamente para temperaturas mais elevadas. Estes modelos podem fornecer informações úteis sob o ponto de vista da segurança alimentar de forma a possibilitar a determinação da vida útil de alimentos com uma margem de segurança razoável.

\section{REFERÊNCIAS}

BARANYI, J.; ROBERTS, T. A. A dynamic approach to predicting bacterial growth in foods. Int. J. Food Microb., v. 23, p. 277-294, 1994.

CARDOSO, T. G.; CARVALHO, V .M. Toxinfecção alimentar por Salmonella spp. Rev. Inst. Ciênc. e Saúde, n. 24, p. 95-101, 2006.

COMBASE. Combasemodelling toolbox. $\quad$ Disponível em http://www.combase.cc/toolbox.html\#DMFit. Acesso em 02 de Março de 2014.

COSTAlunGA, S.; TONDO, E. C. Salmonellosis in Rio Grande do Sul, 1997 to 1999. Braz. J. Microb., v. 33, n. 4, p. 342-346, 2002.

DARWIN, K. H.; MILLER, V. L. Molecular basis of the interaction of Salmonella with the intestinal mucosa. Clin. Microb. Rev., v. 12, n. 3 , p. 405-28, 1999.

FUNK, J. A.; DAVIES, P. R.; NICHOLS, M. A. Longitudinal study of Salmonellaenterica in growing pigs reared in multiple-site swine production systems. Vet. Microb., n.83, p.45-60, 2001.

GYLES, C. L.; PRESCOTT, J. F.; SONGER, G.; THOEN, C. O. Pathogenesis of bacterial infections in animals. Iowa StateUniversity: Ames, v. 2, 1993, p. 133-153.

HALD, T. Harvest epidemiology of Salmonellacontamination in EU pig slaughterhouses. Proceedings of the 3rd International Symposium on the Epidemiology and Control of Salmonella in Pork, Washington, D.C., p. 273-276, 1999.

MCCLURE, P. J.; BLACKBURN, C. W.; COLE, M. B.; CURTIS, P. S.; JONES, J. E.; LEGAN, J. D.; OGDEN, I. D.; PECK, M. W.; ROBERTS, T. A.; SUTHERLAND, J. P.; WALKER, J. S. Modelling the growth, survival and death of microorganisms in foods: the UK Food Micromodel approach. Int. J. Food Microb., v. 23, p. 265-275, 1994.

MCMEEKIN T. A.; OLLEY, J.; ROSS, T.; RATKOWSKY, D. A. Predictive Microbiology: Theory and Application. Research Studies Press Ltd. Taunton, U.K., 1993, 340p.

REIS. T. Intoxicação alimentar atinge 480 funcionários de frigorífico em SC. Folha de São Paulo, São Paulo, 17 de Novembro de 2006. Cotidiano. Disponível em: http://www1.folha.uol.com.br/folha/cotidiano/ult95u128351.shtml. Acesso em 04 de Março de 2014.

SILVA JR., E. A. Manual de controle higiênico sanitário em alimentos. $4^{\mathrm{a}}$ Ed. São Paulo: Varela; 2001, 479p.

SINGH, A.; KORASAPATI, N. R.; JUNEJA, V. K.; SUBBIAH, J.; FRONING, G.; THIPPAREDDI, H. Dynamic Predictive Model for the Growth of Salmonella spp. in Liquid Whole Egg. J. Food Sci., v. 76, p. M225-M232, 2011. 